\title{
ETNOLOGÍA COGNITIVA. ANÁLISIS CONCEPTUAL FUNCIONAL DE PRODUCCIÓN IDIOMÁTICA
}

\author{
Emilio Rivano Fischer
}

\begin{abstract}
RESUMEN
Las expresiones idiomáticas producen "categorías populares”, que son conceptos estables y claves que moldean nuestro entendimiento cotidiano. Las expresiones traen escenas o imágenes, que requieren ser transformadas en las categorías populares en juego. Se describen dos procedimientos que logran este propósito. Ambos involucran operaciones esquemáticas de origen kantiano y de la lingüística cognitiva.

Palabras clave: proyección esquemática, marco semántico, metáfora, metonimia, concepto, imaginación.
\end{abstract}

\begin{abstract}
Idiomatic expressions produce "popular categories", key and quite stable concepts that shape everyday understanding. The expressions bring scenes or images that need to be transformed into the popular category or categories at play. Two procedures are described by which this is achieved. Both imply schematic operations of Kantian and cognitive linguistics origin.

Key words: schematic projection, semantic frame, metaphor, metonimia, concept, imagination
\end{abstract}

\section{Introducción}

Introduzco en este espacio algunas herramientas para desarrollos en este campo que llamamos, vagamente, etnología cognitiva. La noción se relaciona en parte con lo que Chomsky denomina en discusiones informales "ethnoscience", es decir, estudios en torno a conceptos populares que organizan nuestro conocimiento común del mundo. No interesa definir a priori el

Emilio Rivano Fisher. Doctor en Filosofía de la Universidad de Lund. Docente de la Universidad de Stanford. Sede Santiago de Chile.

Correo electrónico: erivano@juno.com

Recepción: 26- 10- 2009

Aceptación: 11- 01- 2010 
campo, sino desarrollar métodos de incursión que sean provechosos, que abran terreno de cultivo. De hecho, las muestras que recogemos, los conceptos que llamamos "categorías populares" son productos más bien de entendimiento social y existencial que de conocimiento de la realidad física o de la naturaleza. Sin embargo, no son las muestras en sí lo que ocupa principalmente a esta presentación, sino los mecanismos que las producen. El método exhibe un diseño funcionalista que opera con ideas de origen kantiano y nociones y herramientas que se asocian a la escuela cognitivista que en otros textos he llamado "californiana" (e.g. Lakoff \& Turner 1989; Lakoff 1993; Fauconnier 1997; Rivano 1997 y 2004). Se trata de herramientas de mediana a baja precisión que, sin embargo, tienen la ventaja de ser de manejo relativamente fácil y "amistoso" y que producen ciertos resultados. Centraremos los desarrollos en producción idiomática.

\section{Materia prima, mecanismo, función}

Las expresiones idiomáticas son objetos lingüísticos involucrados en procesos que cumplen con ciertas funciones. Abstraemos de éstas la función que llamamos de producción de categorías populares. Estos productos se logran a través de un mecanismo que opera sobre cierta materia prima. La materia prima es de naturaleza variada: objetos de la percepción, productos del hombre, modelos folklóricos de animales, escenas tipificadas, situaciones convencionales. Lo que precisa la definición de este objeto que es la expresión idiomática son los mecanismos cognitivos y las funciones primarias del proceso. Como se dijo, una función primaria general del proceso es la de producción de categorías populares. El mecanismo es un conglomerado de operaciones cognitivas, entre las que encontramos metáforas, metonimias y una variedad de tipos de proyección esquemática.

Ilustremos preliminarmente. Una expresión como "más vale tarde que nunca", es un producto que sólo marginalmente ha requerido de un mecanismo de proyección esquemática. La expresión significa que, aunque a destiempo, es mejor hacer algo comprometido, que no hacerlo en absoluto. El significado se ha logrado sin otros requerimientos semánticos más que el sentido convencional de las palabras y su composición (aunque hay proyección metafórica en "valer", asunto que es secundario para el significado proverbial que se logra.) En la expresión "las apariencias engañan", igualmente, se logra el significado general del caso con apego al significado literal de las palabras en el compuesto. En cambio, en la expresión "no todo lo que brilla es oro" se ha creado la categoría popular de "engaño en la apariencia de las cosas" a través de una imagen concreta, los objetos brillantes, y la sugerencia de una escena de búsqueda de oro entre éstos. Para producir ese significado requerimos de operaciones que proyecten esa escena original al ámbito esquemático de la categoría de "engaño en la apariencia”. Es, grosso modo, el ámbito que comparten las infinitas variaciones del tema, variaciones entre las que se encuentra no sólo la situación aludida en la expresión, sino la situación de uso o aplicación de la expresión. (La expresión ocurre en una "forma de vida". Sin embargo, como veremos, el uso no es dimensión que importe focalmente en estos desarrollos, sino, más bien, las condiciones semánticas del uso de la expresión, es decir, los rasgos que establecen su "gramática"). En forma más específica, requerimos que se proyecte lo que interesa del dicho a la situación concreta de uso.

Tanto "más vale tarde que nunca", como "las apariencias engañan" y "no todo lo que brilla es oro", son, en términos tradicionales, proverbios. El criterio es el de "expresión concisa y acuñada que trae una enseñanza", "fórmula concisa del conocimiento acumulado", etc. Pero, como vemos, sólo esta última presenta su categoría de modo concreto e indirecto y, al hacerlo, 
implica un procedimiento particular. El término "expresión idiomática" podrá concebirse, entonces, en forma más restrictiva y apuntar a éste último tipo de objetos. Eventualmente, términos más descriptivos como "expresión idiomática conceptual" o "expresión idiomática con proyección esquemática” podrán emplearse para evitar confusión.

\section{Categoría popular}

Atendiendo a su función, el producto que arrojan, podemos definir las expresiones idiomáticas como mecanismos lingüísticos de producción de categorías populares. Las categorías populares son focos de interés humano universal y son también nociones que organizan nuestro entendimiento del mundo. Entre éstas se encuentran la justicia, la deuda, el engaño, la traición, la mentira, el aprovechamiento, la torpeza, el genio, el acierto, la suerte, el accidente, la tragedia, la salvación, el problema, la idiotez, el error, entre otras incontables. Las categorías populares son los objetos mismos de nuestra atención y orientación social. En la expresión idiomática encontramos un procedimiento para nombrar y establecer la categoría en su nivel de idea o concepto, a través de la experiencia concreta. También podemos expresarlo así: la categoría empírica en la expresión idiomática se emplea para representar la noción abstracta, el concepto general que es la categoría popular del caso. Las expresiones idiomáticas son el mecanismo cotidiano para nombrar estas categorías en sus infinitas variaciones.

El habla cotidiana "convencional" es frecuentemente expresión idiomática: vista a través de los instrumentos que desarrollamos, muchas veces no hay diferencia en la naturaleza de ambas. Por ejemplo, una expresión cotidiana como "un choclón (de gente)" es también una expresión idiomática, significa una categoría popular, el gentío, la aglomeración, el tumulto, y lo hace usando la materia prima de una imagen simple y de experiencia "directa": la aglutinación de granos en el choclo (o de bolitas o canicas en un hoyo). Una expresión cotidiana como "abrir espacio" es una expresión idiomática, significa "apartar", "dar lugar", "crear espacio para el movimiento o la acción”, y lo hace a través de las imágenes de abrir objetos.

Por su parte, hay dichos, es decir, productos que traen una enseñanza, una instrucción o un consejo, que son también expresiones idiomáticas, por manifestar, por un mecanismo característico, una categoría popular (y servir, dado el caso, para esa indicación, más que para instruir.) Por ejemplo, el dicho "No le pidas peras al olmo" significa las categorías de futilidad, imposibilidad y estulticia. El dicho es la expresión idiomática de una categoría popular: el intento idiota de algo imposible (o la gestión absurda, la porfía en lo irrealizable, la obstinación quimérica, etc.). El proverbio chino “¿Buscas pescado? No subas al árbol” presenta, a su manera, la misma categoría popular. Figuramos de mil modos esta categoría: "pellizcar un vidrio", "escribir en el agua", "morderse la nuca", "hacer una escalera al cielo", "cuadrar el círculo". Y -lo que importa advertir- cada vez que se aplica la expresión en un contexto de uso, una variación particular de la categoría popular se manifiesta. La categoría es un universal concreto, en la diferencia.

En uso, la expresión no necesariamente funciona como instrucción -lo que caracteriza a la noción de dicho-. Alguien puede simplemente describir la acción de otro expresando "le está pidiendo peras al olmo", e indicar así la categoría que la califica. Cuando una mamá le insiste al infante de seis meses que diga "abuelita", le está pidiendo peras al olmo. Cuando los políticos y burócratas chilenos decidieron instalar en los microbuses de Santiago máquinas para que la gente pagara por esa vía, le estaban pidiendo peras al olmo. Cuando Allende le 
fue a pedir apoyo financiero y tecnológico a la Unión Soviética, le estaba pidiendo peras al olmo. Bush pedía peras al olmo en Irak, si (verdaderamente) pretendía que se montara allí un sistema político occidental. (Cuando se reflexiona sobre el punto, el olmo resulta ser un peral muy popular y abundante.)

\section{Aplicación: escena original, metonimia, marco semántico, selección esquemática, proyección esquemática}

Ensayemos con mayor detalle de análisis. Retomemos la expresión "pedirle peras al olmo". Imaginemos un contexto de uso en torno a lo siguiente: A una persona que no es diestra en ingeniería se le encarga que resuelva un problema complicado de resistencia de materiales. Alguien exclama al solicitante "¡no le pidas peras al olmo!” o “¡le estás pidiendo peras al olmo!", etc.

El contexto de uso es una suerte de juego de lenguaje en nomenclatura wittgensteineana. Sin embargo, el análisis de la expresión que interesa no es pragmático, sino conceptual y cognitivo: buscamos establecer el tipo de entendimiento que se produce y los mecanismos que han llevado a ello. Indagamos sobre la naturaleza específica de la expresión en contexto, pero no por su uso, sino por su significado.

En la escena original, alguien recolecta peras y busca en un olmo, sin encontrar ninguna. Pasa otro y le dice "no le pidas peras al olmo". Entre la gama de categorías populares que se producen de esta expresión idiomática encontramos "intento imposible", "deseo frustrado", "pretensión absurda", "esfuerzo inútil”, "acción fútil”, "acto ridículo", "acto necio". Como vemos, alguna o algunas de éstas son las que se producen en el contexto de uso del caso. Se trata del tipo de entendimiento que de hecho se ha producido. A estos tipos de entendimiento llamamos "categorías populares". Son objetos relativamente estables de nuestra conceptualización cotidiana. Nuestro lenguaje común busca constantemente expresarlos. Una manera de hacerlo es la formación de expresiones idiomáticas.

Para fabricar estas categorías a partir de la escena original en la expresión requerimos de operaciones que transformen ese origen en esos productos. Para ello, debemos trascender el nivel de las peras y de los olmos. Una primera operación reproduce el original en formato esquemático. La escena original referida se proyecta en la siguiente secuencia de marcos semánticos:

(A)

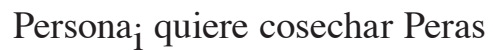

Peras se cosechan sólo en Peral

Persona $_{i}$ intenta cosechar Peras en Árbol Olmo

Persona $_{i}$ no cosecha Peras

Una segunda etapa debe proyectar el nivel esquemático relativamente específico en (A) a un nivel genérico tal que nos abstraiga del ámbito de las peras y de los olmos. Para ello, (a) operaciones metonímicas transforman los elementos específicos "Peras", "cosechar" y "Peral" en los elementos genéricos "recursos", "extraer" y "fuente de recursos", respectivamente (LAS PERAS SON RECURSOS, COSECHAR ES EXTRAER EL RECURSO, EL PERAL ES UNA FUENTE DE RECURSOS) y (b) el esquema A se proyecta en el esquema B por medio de una operación que borra lo específico y deja lo genérico. También podría decirse que la 
operación del caso proyecta el esquema escénico (específico) original a un esquema genérico (no-escénico, abstracto). (Cf. la noción de “metáfora de LO GENÉRICO ES ESPECÍFICO” en Lafoff \& Turner (1989), que, desde nuestra perspectiva y en esta etapa de la derivación, habría que nombrar más bien macro-metáfora de LO ESPECÍFICO ES GENÉRICO, es decir, una operación que automáticamente nos hace ver lo genérico en lo específico (y lo específico en lo genérico, vid infra). Esta proyección produce el siguiente esquema genérico:

(B)

Persona $a_{i}$ intenta extraer Recurso

Recurso se obtiene sólo de Fuente FR

Persona $_{i}$ intenta extraer Recurso en Objeto O

Persona $a_{i}$ no obtiene Recurso

Hay proyecciones alternativas. Por ejemplo, otra versión de esto, bajo operaciones metonímicas particulares (tales como "QUERER COSECHAR ES PRETENDER LOGRO”, etc.), podría derivar en el esquema (C):

(C)

Persona $a_{i}$ pretende Logro

Logro se obtiene sólo por Medio ML

Persona $_{i}$ pretende Logro por Medio MO

Persona $_{i}$ no obtiene Logro

Es necesario que el contexto de uso obtenga este entendimiento, por lo que cabe proyectar el nivel genérico esquemático producido sobre dicho contexto (llamémoslo CU). Algo así como la siguiente proyección desde el esquema (B) a CU:

(B) a CU

Recurso en (B) es solución de problema de resistencia de materiales en CU

Fuente FR (donde se obtiene el Recurso) no existe en CU

Objeto $\mathrm{O}$ en (B) es persona que no es diestra en ingeniería en $\mathrm{CU}$

Persona $_{i}$ en (B) es solicitante en CU

Proyectando los roles de (B) en CU obtenemos el entendimiento buscado (que no es sino una lectura posible de CU). Esta es la contrapartida de la operación anterior (cf. la noción de "blending" (mixtura) en Fauconnier \& Turner 1996). Se trata de una operación que nos hace ver lo específico en lo genérico. La proyección devuelve a CU la estructura genérica extraída de la expresión idiomática.

Requerimos operaciones adicionales para llegar a las categorías populares que interesan. En este caso, podemos derivar a partir de una lógica semántica o de relaciones analíticas. Por ejemplo, de B1 obtenemos “intento" y de B3 dado B2 obtenemos “imposible”, es decir, "intento imposible", que es una de las categorías que eventualmente se busca producir a través de esta expresión. De B3 y B4 obtenemos "intento frustrado". De B3 dado B2 obtenemos "intento absurdo" y, dado B4, "intento ridículo" y también "intento necio".

Derivamos de lo anterior sugerencias de candidatos a lo que podemos nombrar "universales etnológicos" o "universales conceptuales". Por ejemplo, la figuración o metáfora genérica del LO IMPOSIBLE COMO EXTRACCIÓN DE RECURSO FUERA DE FUENTE DE RECURSO es un candidato y RIDÍCULO o NECEDAD COMO INTENTO IMPOSIBLE DE OBTENER RECURSO es otro. Es decir, se trata de apareamientos 
esquemático-conceptuales cuya validez etnológica generalizada queda expuesta a la prueba: ¿Se realizan las categorías del caso a través de estos esquemas y apareamientos en las distintas comunidades/culturas?

El análisis puede afinarse. Dejaremos este ejemplo en este punto. La expresión idiomática "pedirle peras al olmo" aporta una materia prima que ha requerido de una serie de operaciones cognitivas para producir las categorías populares que son, finalmente, el entendimiento del caso. En esta aplicación, la fábrica que ha producido estas categorías populares ha empleado escena original, marcos semánticos, metonimias, distintos tipos de proyecciones esquemáticas y una lógica semántica o de relaciones analíticas.

El método podrá aplicarse en forma similar a toda expresión idiomática que formule una escena original. Tales objetos constituyen series infinitas de formación lingüística. Algunos de ellos son convencionales y se encuentran arraigados y expandidos por doquier, como "meter la pata", "cortar el queso", "pagar el pato", "dorar la píldora", "ahogarse en un vaso de agua". Otros son locales y emergentes, como (chileno) "sacarse el pillo", "irse al chancho", "irse en collera", "matar la gallina", "pararle el carro a alguien", "andar a patadas con las pulgas", "hacerse la mosquita muerta", entre incontables otras.

\section{Aplicación: metáfora}

Veamos la expresión "estar frito”. Imaginemos el siguiente contexto: "a mi pareja no le ha llegado su período desde hace dos semanas: ¡estoy frito!”. Supongamos la imagen original de un pescado frito (hay otras imágenes culinarias posibles). Un pescado frito puede integrarse en infinitas escenas y marcos semánticos. Necesitamos producir las categorías populares de "derrota inminente", "desastre", "problema sin solución", "dificultad sin salida", entre otras. De modo que la perspectiva, dada esa imagen, debe ser la del pez: Nuestro protagonista, que nadaba libremente en el océano infinito, ha sido pescado, faenado y está ahora en la paila friéndose o en el plato a punto de ser ingerido. No puede escapar. Está literalmente frito.

Lo anterior equivale a una secuencia plausible para iniciar una derivación esquemática en términos de las escenas involucradas. Sin embargo, observamos que la expresión "frito" se agrupa con otras que coinciden parcialmente en el tipo de categorías que producen y la manera de producirlas. Así, por ejemplo, nos encontramos con expresiones como "al Manuel lo tienen cocinado ya" (en el sentido de que ya no puede ganar, o no puede hacer nada por librarse o escapar de una situación), "en ese campeonato, ese atleta se los comió a todos los otros" (en el sentido de haberlos vencido a todos), "cuando se descubrió su desviación sexual, a ese político la prensa lo fue desmenuzando de a trocitos" (en el sentido de sacarle provecho minuciosamente), "un asunto cocido y sacramentado" (en el sentido de acabado, sin posibilidad de ser revertido), "muerto y faenado" (en el sentido de vencido, derrotado), "vamos a trozar a nuestro enemigo por partes" (en el sentido de vencerlo o liquidarlo lenta o metódicamente), "déjalo que se sazone por ahora" (en el sentido de esperemos antes de comenzar a liquidarlo), "cuando un famoso cae, la prensa se deleita y, tenedor y cuchillo en mano, lo va engullendo lenta y apetitosamente" (en el sentido de servirse largamente de esa caída o derrota).

Lo que vemos en esta riqueza expresiva es la realización lingüística (parcial) de una metáfora. Podemos nombrarla de varias maneras: SER DERROTADO ES SER ALMORZADO, VENCER ES COMER, LUCHAR ES ALIMENTARSE, EL ENEMIGO ES COMIDA, VENCER ES OBTENER COMIDA, LA CONTIENDA ES LA PROCURACION DEL ALIMENTO. Una metáfora es un apareamiento entre dos ámbitos de la realidad. En este 
caso, los ámbitos son los de la contienda, el conflicto, la lucha, por un lado, y la procuración e ingestión de alimentos, por el otro. (Para introducciones a la metáfora desde estas perspectivas, v.g. Lakoff \& Johnson 1980; Rivano 1997 y 2002). Esta metáfora estructura (aspectos de) asuntos conflictivos, asuntos competitivos, asuntos de victorias y derrotas, de vencedores y vencidos, en términos de (aspectos de) la alimentación.

Desde estas consideraciones, la expresión "frito" en el contexto del caso produce las categorías populares de "derrota inminente", "desastre", "problema sin solución”, "dificultad sin salida", entre otras, por el expediente de ser una realización lingüística de la metáfora que aparea CONFLICTO (o CONTIENDA o LUCHA, etc.) con ALIMENTACIÓN. Esa ha sido la operación central que ha producido las categorías del caso a partir de la materia prima de un pescado frito.

Sin entrar en detalles sobre su estructura interna y los principios y condiciones que regulan la productividad lingüística a que da lugar, podemos decir en líneas generales que la metáfora funciona como una licencia. En este caso, algo así como lo siguiente: puede usted expresarse a propósito de los conflictos como si se tratara de asuntos alimenticios, se lo garantiza la metáfora LOS ASUNTOS CONFLICTIVOS SON ASUNTOS DE ALIMENTACIÓN. Esta metáfora, que aparea CONFLICTO con ALIMENTACIÓN (VENCER con COMER, ENEMIGO con ALIMENTO, etc.), se sugiere como otro candidato a universal etnológico.

El método aplica a toda expresión que sea realización de alguna metáfora. Por ejemplo, una expresión como "se picó cuando le dije que no lo invitaríamos a la fiesta" (en el sentido de "se enfadó", "se molestó") puede derivarse de la metáfora OÍR PALABRAS o ENTENDER LENGUAJE ES INGERIR COMIDA (v.gr. "palabras dulces", "un discurso delicioso", "amargas frases", "palabras que caen pesado", "autor indigestivo", "obra nutritiva", etc.) o acaso de una metáfora como LAS IMPRESIONES SON IMPRESIONES GUSTATIVAS ("me gusta esa música”, "iqué rato más desagradable”, "una experiencia exquisita”, "iqué picante esa persona!", “obra jugosa”, "personalidad desabrida”, “asunto salado", etc.). Esas serían las operaciones centrales que producirían categorías como las de "enojo" o "irritación psicológica" a partir de la materia prima del picante o ají culinario. Una expresión como "María y Manuel son uña y carne" (en el sentido de "pareja inseparable", "pareja afín") produce las categorías de "unión fuerte", "relación indisoluble", entre otras. La expresión es realización de la metáfora LAS RELACIONES SON ADHESIONES, apareamiento desde el que también se producen expresiones como "se separaron" (en el sentido de término de la relación), "es un caluga" (en el sentido de una persona que insiste y fastidia con su presencia), "es un pegote" (en el sentido de una persona que fastidia con su proximidad). Por medio de esa metáfora, entonces, la expresión "ser uña y carne" logra producir las categorías de "unión fuerte", "lazo amoroso", "relación íntima", entre otras.

\section{Imaginación}

La función de las expresiones idiomáticas es la producción de categorías populares. Emplean para ello la materia prima de la experiencia y la cognición inmediatas: percepción sensorial, interacción con objetos y con el medio, escenas y situaciones básicas, experiencia y conocimiento convencional. Esa materia prima se procesa en operaciones cognitivas: metáforas, metonimias y otras proyecciones y manipulaciones esquemáticas. Los productos son las categorías populares, elementos en nuestro entendimiento cotidiano y generalmente irreflexivo del mundo. 
En forma vaga el término "imaginación” puede emplearse para nombrar la dimensión en donde ocurren estas operaciones. En forma algo más precisa, el término es propio de los procedimientos de generación y aplicación de imágenes (de todo tipo) para producir significados.

Como se aprecia, la materia prima de la fabricación de significado idiomático es de naturaleza esquemática, de modo que es el producto de un proceso de generación anterior, más primario. El carácter básico de las imágenes en esta materia prima, la tradición kantiana en torno a los esquemas y la anterior en torno a la "fantasía" y su contrapartida latina "imaginación", hacen de este último término una manera adecuada para referirse a los procesos de producción de categorías y lenguaje idiomático. De modo que Etnología de la Imaginación habría sido quizás una indicación más feliz para referirnos a estas incursiones.

\section{Diseño funcional general}

Cerremos este esbozo con una nota de resumen. Con respecto a los mecanismos de producción de categorías populares en las expresiones idiomáticas, nos orientamos por un diseño funcional: hay una fábrica o complejo de mecanismos que procesa una materia prima para producir un producto. Los productos son las categorías populares, significados relativamente estables y de interés común. La especificación de diseño es cumplir con la función de producir estas categorías. La materia prima son fenómenos inmediatos: percepciones, experiencias cotidianas, manejos instrumentales, escenas básicas, situaciones convencionales, conocimiento convencional. Los mecanismos son varios. Los llamamos operaciones cognitivas. Como hemos dicho, contemplan metáforas, metonimias y otras operaciones de proyección y manipulación esquemática.

Enfrentados a una expresión idiomática, presenciamos el producto y la materia prima. El producto es el significado que se nos presenta como intuición inmediata y sobre lo que podemos obtener amplio acuerdo intersubjetivo. Allí se encuentran las categorías populares, sobre lo que también se espera acuerdo común, si bien el establecimiento de las categorías en juego en cada caso requiere de criterios de interpretación. La materia prima es el material con el que se construye ese significado: percepciones, objetos, propiedades, experiencias, escenas, situaciones, conocimiento convencional. Es el plano de la imaginación. Igualmente, habrá acuerdo general en este punto, si bien se verá que es flexible y alternante esta fuente en la producción de expresiones idiomáticas. El mecanismo de construcción es lo que debe postularse en el análisis. El mecanismo es la complejidad interior, diseño que responde a la siguiente cuestión: ¿Cómo se produce este significado a partir de esta materia prima? El mecanismo es la "computación" que resuelve el problema. Es la fábrica semántica del caso: el conjunto de operaciones que produce significado a partir de la materia prima.

Finalmente, el método se presenta como un conjunto de herramientas prácticas para avanzar en el terreno que aquí vagamente se ha llamado de etnología cognitiva. Se trata de una indicación, no de un programa establecido. En este caso, hemos aplicado ciertas técnicas para aproximarnos a estos focos básicos de nuestro entendimiento cotidiano y de nuestra orientación social que son las categorías populares.

\section{Bibliografía}

Fauconnier, Gilles \& Mark Turner. 1996. "Blending as a Central Process of Grammar”. En Goldberg (ed.) 1996: 113-130. 
Fauconnier, Gilles. 1997. Mappings in Thought and Language. Cambridge: Cambridge University Press.

Goldberg, Adele (ed.). 1996. Conceptual Structure, Discourse and Language. Stanford: Center for the Study of Language and Information.

Lakoff, G.\& Mark Johnson. 1980. Metaphors We Live By. Chicago: The University of Chicago Press.

Lakoff, G. \& Mark Turner. 1989. More than Cool Reason. Chicago: The University of Chicago Press

Lakoff, George. 1993. “The Contemporary Theory of Metaphor” en Ortony (ed.) 1993: 202-251.

Ortony, Andrew (ed.). 1993. Metaphor and Thought. Cambridge: Cambridge University Press.

Rivano, Emilio.1997. Metáfora y Lingüística Cognitiva. Santiago de Chile: Bravo y Allende Editores

2002. Seven Lessons on Metaphor. Concepción: Universidad de Concepción \& Bravo y Allende Editores.

2004. De las Expresiones Idiomáticas. Concepción: Cosmigonon. Serie Lingüística Universidad de Concepción. 
